\title{
Aminoguanidine treatment reduces the increase in collagen stability of rats with experimental diabetes mellitus
}

\author{
H. Oxlund and T. T. Andreassen \\ Department of Connective Tissue Biology, Institute of Anatomy, University of Aarhus, Aarhus, Denmark
}

\begin{abstract}
Summary. Alterations in the biophysical properties of connective tissues in diabetes mellitus have been attributed to the nonenzymatic glycation of the collagens and the subsequent formation of browning products, cross-linking the proteins. Aminoguanidine may bind to carbonyl groups of these nonenzymatic glycation products and thereby block the process. Rats with streptozotocin-induced diabetes were treated with aminoguanidine, $25 \mathrm{mg} \cdot \mathrm{kg}^{-1} \cdot \mathrm{day}^{-1}$, for 120 days. The aminoguanidine treatment did not counteract the increase in blood glucose concentrations, nor did it prevent the arrest in weight gain of diabetic rats. The increased stability in $7 \mathrm{~mol} / \mathrm{l}$ urea and increased tensile strength of tail tendons from the diabetic rats, however, were prevented by the aminoguanidine treatment. Aminoguanidine did not reduce the formation of early nonenzymatic glycation products
\end{abstract}

(aldimine and Amadori rearrangement products), whereas the amount of browning products (fluorescent compounds) was reduced in the tail tendon collagen of the diabetic rats. Aminoguanidine treatment of intact rats did not influence these parameters. These findings indicate that the biophysical alterations of collagens induced by experimental diabetes are caused by cross-links derived from the nonenzymatic glycation, and furthermore, that aminoguanidine treatment may prevent the concomitant changes in biophysical properties of connective tissues.

Key words: Diabetes mellitus, nonenzymatic glycation, collagen, aminoguanidine, collagen cross-links, browning products, advanced glycation end-products.
Abnormally high glucose levels over a period of many years, as sometimes found in diabetic patients, may result in impaired function of tissues. The cause of these complications seems to be multifactorial. One of the factors may be the nonenzymatic glycation and subsequent formation of browning products resulting in irreversibly cross-linked proteins [1-4]. Such alterations would be expected to affect the biomechanical properties of connective tissues, because collagens are long-lived proteins which possess $\varepsilon$-amino groups of lysyl and hydroxylysyl residues. Increased biomechanical strength of collagens has been found in vitro after incubation of rat tail tendons with glucose [5-8] and in vivo in animals with experimental diabetes $[9,10]$. In a recent study we found a marked increase in the stiffness of the aortic tissue taken outside areas of atherosclerosis in diabetic subjects [11]. It has been reported that the nucleophilic hydrazine compound aminoguanidine may inhibit the formation of cross-linking products derived from the nonenzymatic glycation $[12,13]$. Aminoguanidine is believed to block the reactive carbonyl groups of the nonenzymatic glycation products (Fig.1).
The mechanical strength and stability of newly synthesized collagen fibrils, however, are dependent on the formation of covalent cross-links between the collagen molecules, and these cross-links involve enzymatic reactions. The initial step of their formation is the oxidative deamination of specific lysine and hydroxylysine residues resulting in aldehyde groups which can condense with the $\varepsilon$-amino groups of the lysine and hydroxylysine residues, and with histidine residues of adjacent molecules. The condensation products can be detected by reduction with tritiated borohydride, acid hydrolysis and amino acid analysis. The two major reduced compounds that can be isolated from rat tail tendon collagen are hydroxylysinonorleucine (HLNL) and histidinohydroxymerodesmosine (HHMD) $[5-7,10]$.

The present experiment analyses changes in the stability and biomechanical properties, in the formation of early nonenzymatic glycation and browning products and in the reducible cross-links in collagen of rats with experimental diabetes. A group of diabetic rats was injected daily with aminoguanidine in order to study if blockage of the nonenzymatic glycation prevents the alterations in the 


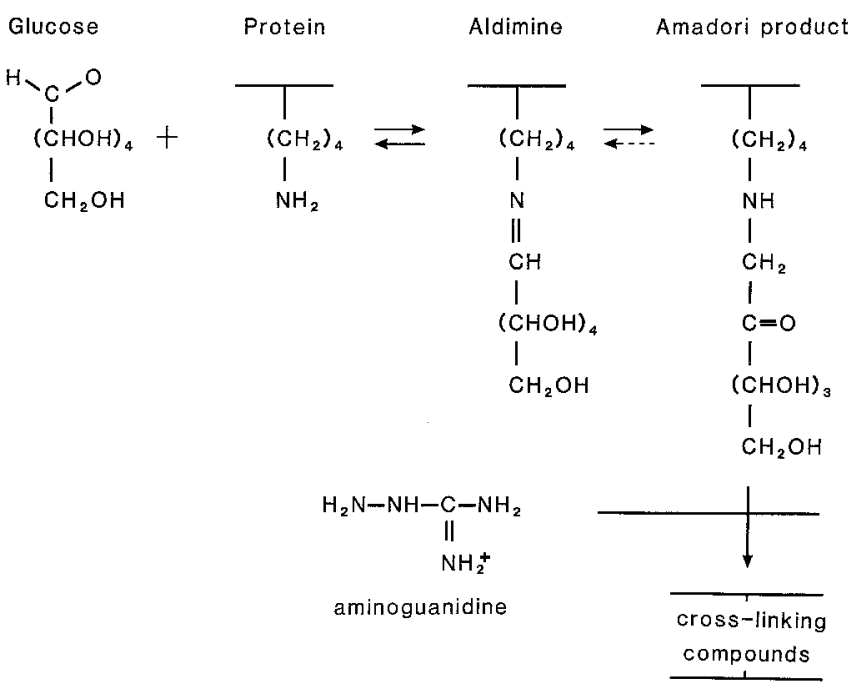

Fig.1. Aminoguanidine inhibition of formation of browning crosslinking compounds. Schematic representation of glucose binding to $\varepsilon$-amino groups of lysyl residues in protein, formation of an aldimine group (Schiff base), the irreversible Amadori rearrangement and subsequent dehydration steps resulting in browning products which cross-link proteins. Aminoguanidine may bind to the reactive carbonyl groups of the glycation products and block the formation of cross-linking compounds (browning products)

biomechanical properties of collagenous fibres induced by diabetes. Furthermore, a group of intact rats was treated with aminoguanidine to evaluate if aminoguanidine by itself influences these parameters.

\section{Materials and methods}

Seventy-six male Wistar rats were used. At the start of the experiment the rats were 90 days old. They were randomized into six groups of 12-15 rats each (Table 1): (1) an intact control group, (2) an isotonic $\mathrm{NaCl}$ (saline) control group, (3) a saline-injected diabetic group, (4) an aminoguanidine-treated diabetic group, (5) an aminoguanidine-treated control group and (6) a food-restricted group treated with saline. The duration of the experiment was 120 days.

Diabetes was induced by an intraperitoneal injection of streptozotocin $\left(55 \mathrm{mg} \cdot \mathrm{kg}^{-1}\right)$. Blood glucose levels were determined during the experimental period with blood from the cut end of the tails using sticks (BN-test/BG, Boehringer-Mannheim, Mannheim, FRG) employing a reflectance meter (Hypo-count II, Hypoguard Ltd., Woodbridge, UK). The two aminoguanidine-treated groups were injected intraperitoneally with aminoguanidine, $25 \mathrm{mg} \cdot \mathrm{kg}^{-1} \cdot \mathrm{day}^{-1}$, in isotonic saline and the other groups, except for the intact control, were injected daily with the same amount of isotonic saline. The weight gain of diabetic rats is arrested [14] and therefore, the food-restricted group was included. The food-restricted rats were given a fixed amount of rat pellets daily in order to achieve the same weight as the diabetic rats injected with saline. At the end of the experiment, the rats were killed with an overdose of pentobarbital. The tails were cut off, wrapped airtight in plastic film and stored at $-80^{\circ} \mathrm{C}$.

\section{Stability of rat tail tendon collagen}

The stability of rat tail tendons was studied by measuring the breaking time in $7 \mathrm{~mol} / \mathrm{l}$ urea at $40^{\circ} \mathrm{C}$ using a modified method described by Boros-Farkas and Everitt [15]. Briefly, single tendons were pulled out from the tail, wrapped quickly in parafilm, and the weight and length of each tendon were determined. The tendon was suspended by a clip, and a weight corresponding to $50 \mathrm{~g}$ per $\mathrm{mg} \cdot \mathrm{mm}^{-1}$ tendon was fastened by another clip to the other end of the tendon. Then it was immersed in a glass tube containing a $7 \mathrm{~mol} / \mathrm{h}$ urea solution at $40^{\circ} \mathrm{C}$. The time until rupture of the tendon was recorded. Four tendons from each rat were studied and a mean breaking time calculated for each rat. The mean coefficient of variation was $17.2 \%$.

\section{Analysis of biomechanical properties}

Single tendon fibres were wrapped quickly in parafilm, and the weight and length were determined. During the test procedure they were immersed in Ringer's solution, $\mathrm{pH} 7.4$, and mounted in a materials testing machine (TCT5, Lorentzen and Wettre, Stockholm, Sweden) with a distance between the clamps of $10 \mathrm{~mm}$. They were stretched at a constant speed of $20 \mathrm{~mm}$ per min. Load-deformation curves were obtained continuously and converted into "stress"strain curves as previously described $(7,16)$. "Stress" values were expressed as load values per $\mathrm{mg}$ wet weight per mm tendon. Strain values were calculated as deformation values divided by the original length of each sample, i. e. relative elongation. From these data the following parameters were calculated: strain at maximum "stress", maximum "stress", maximum stiffness, i. e. slope of the linear part of the curve, and relative failure energy, i.e. integrated area under the "stress"-strain curve from the starting point to the breaking point (Fig.2). Six tendon fibres were analysed and used for calculation of a mean curve for each rat.

\section{Determination of hydroxyproline}

Hydroxyproline was determined according to Stegeman and Stalder [17] and expressed in $\mu \mathrm{g}$ per mm tendon length.

\section{Reducible hexosyl-lysines and collagen cross-links}

The amount of glucose attached to the collagen through the $\varepsilon$ amino groups of hydroxylysine and lysine was determined by reduction of the rat tail tendon collagen with tritiated potassium borohydride as previously described $[5,18-20]$. Tail tendons from each rat were washed extensively, immersed in phosphate buffered physiological saline and reduced by adding a solution of tritiated potassium borohydride. After $1 \mathrm{~h}$ at $21^{\circ} \mathrm{C}$ the solution was acidified

Table 1. Weight and blood glucose of diabetic rats treated with aminoguanidine

\begin{tabular}{lcccc}
\hline Group & $\begin{array}{l}\text { Number } \\
\text { of rats }\end{array}$ & $\begin{array}{l}\text { Initial } \\
\text { weight } \\
(\mathrm{g})\end{array}$ & $\begin{array}{l}\text { Final } \\
\text { weight } \\
(\mathrm{g})\end{array}$ & $\begin{array}{l}\text { Final } \\
\text { blood } \\
\text { glucose } \\
(\mathrm{mmol} / \mathrm{l})\end{array}$ \\
\hline Control rats & 24 & 326 & 472 & 4.7 \\
& & \pm 3 & \pm 5 & \pm 0.2 \\
Diabetic rats & 13 & 317 & $295^{\mathrm{a}}$ & $20.8^{\mathrm{a}}$ \\
& & \pm 4 & \pm 13 & \pm 1.2 \\
Diabetic rats & 15 & 322 & $324^{\mathrm{a}}$ & $22.1^{\mathrm{a}}$ \\
+ aminoguanidine & & \pm 5 & \pm 12 & \pm 1.2 \\
Control rats & 12 & 328 & 456 & 4.6 \\
+ aminoguanidine & & \pm 5 & \pm 8 & \pm 0.2 \\
Food-restricted rats & 12 & 326 & $305^{\mathrm{a}}$ & $3.9^{\mathrm{a}}$ \\
& & \pm 5 & \pm 5 & \pm 0.2 \\
\hline
\end{tabular}

Mean values \pm SEM. ${ }^{a} p<0.01$ vs control rat group 


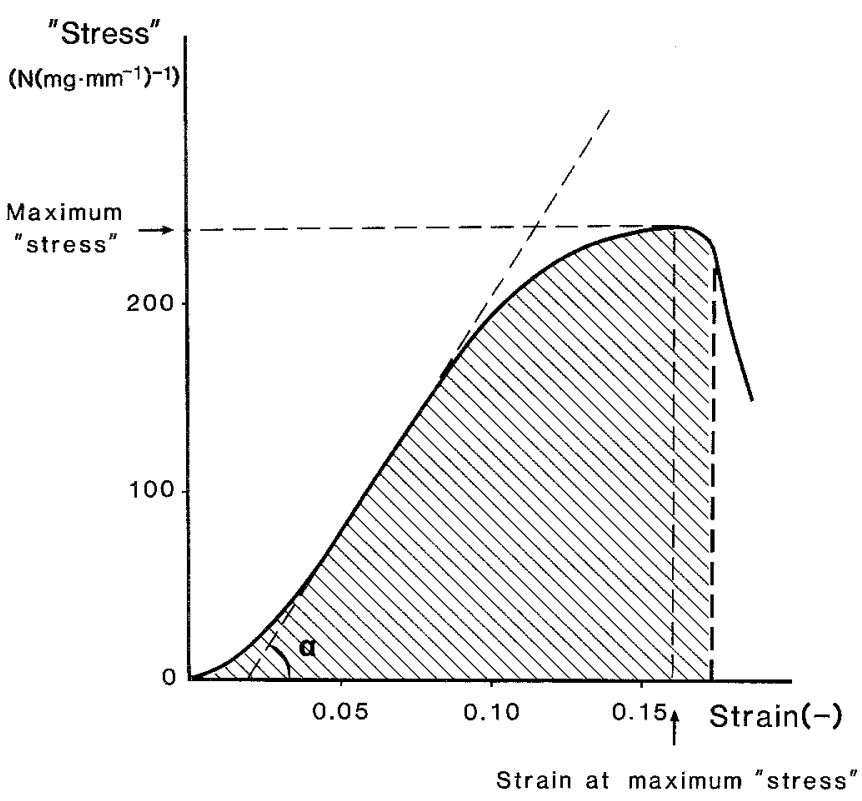

Fig. 2. Rat tail tendons were analysed by means of a materials testing machine. The diagram gives the typical "stress"-strain relationship and parameters of maximum "stress" (tensile strength), strain at maximum "stress" (extensibility) and tangent of the angle $\alpha$ giving the maximum stiffness. N, Newton

to $\mathrm{pH} 4.0$ and dialysed against water for $48 \mathrm{~h}$. The samples were then freeze-dried and hydrolysed in redistilled constant boiling $6 \mathrm{~mol} / \mathrm{l} \mathrm{HCl}$ by refluxing overnight. The hydroxyproline concentration of each hydrolysate was determined as described above. From the remaining part of the hydrolysate the $\mathrm{HCl}$ was removed by evaporation in vacuum, and equal amounts of the hydrolysate were submitted to ion-exchange chromatography using pyridine/formate buffers [18-22]. The fractions were collected and the tritium activity determined in a liquid scintillation counter. The reduced hexosyl-lysines and cross-linking compounds were identified by calibration of the column with standards of glucosyl-hydroxylysine, glucosyl-lysine and dihydroxylysinonorleucine (DHLNL), HLNL and HHMD. These standards were prepared from bone collagen, collagen from rat tail tendons and collagen from rat tail tendons incubated with glucose. Relevant peaks were re-chromatographed using a sodium citrate buffer system [21]. The tritium activity of each peak was expressed in relation to the hydroxyproline content of the hydrolysate.

\section{Fluorescent compounds}

Homogenized samples of the tail tendons were washed in copious amounts of phosphate buffered saline followed by distilled water and precipitated by centrifugation ( $30,000 \mathrm{x} g$ for $30 \mathrm{~min}$ ). The samples were then suspended in a solution of $70 \%$ volume/volume formic acid and bubbled through with nitrogen for $10 \mathrm{~min}$. Solid cyanogen bromide was added under nitrogen (ratio cyanogen bromide/collagen was 1:1). The cyanogen bromide digests were stirred at $30^{\circ} \mathrm{C}$ for $4 \mathrm{~h}$, diluted ten-fold in distilled water, rotary evaporated, taken up in $0.1 \mathrm{~mol} / \mathrm{l}$ acetic acid and freeze-dried. The cyanogen bromide peptides of each rat were dissolved in $50 \mathrm{mmol}$ Tris-buffer, $\mathrm{pH} 7.4$, with $150 \mathrm{mmol} \mathrm{CaCl}$. The samples were centrifuged $(30,000$ $\mathrm{x} g$ for $30 \mathrm{~min}$ ). The relative fluorescence of the supernatants was measured by a spectrophotofluorometer (RF 540, Shimadzu, Japan) at $425 \mathrm{~nm}$ (excitation at $370 \mathrm{~nm}$ ). The fluorescence intensity of a blank was subtracted. The hydroxyproline content in the supernatant and precipitate was measured as described above. The fluorescence intensity was expressed in relation to the hydroxyproline concentration of the supernatant. A mean value for the tail tendons of each rat was calculated from triplicate determinations at three different dilutions of the supernatant.

\section{Statistical analysis}

Mean values \pm SEM were calculated for each rat and for groups of rats. The data were analysed by using the Kruskal-Wallis test and the non-paired Wilcoxon test [23]. Differences were regarded significant if $p<0.05$.

\section{Results}

No differences were found between the intact control and saline control groups, and therefore they were merged into a single control group of 24 rats. The body weight gain of the control rats during the experimental period was $45 \%$ (Table 1 ). The diabetic animals did not gain weight during the experiment and at killing their weight was re-

Table 2. Collagen content, stability and biomechanical parameters of tail tendons from diabetic rats treated with aminoguanidine

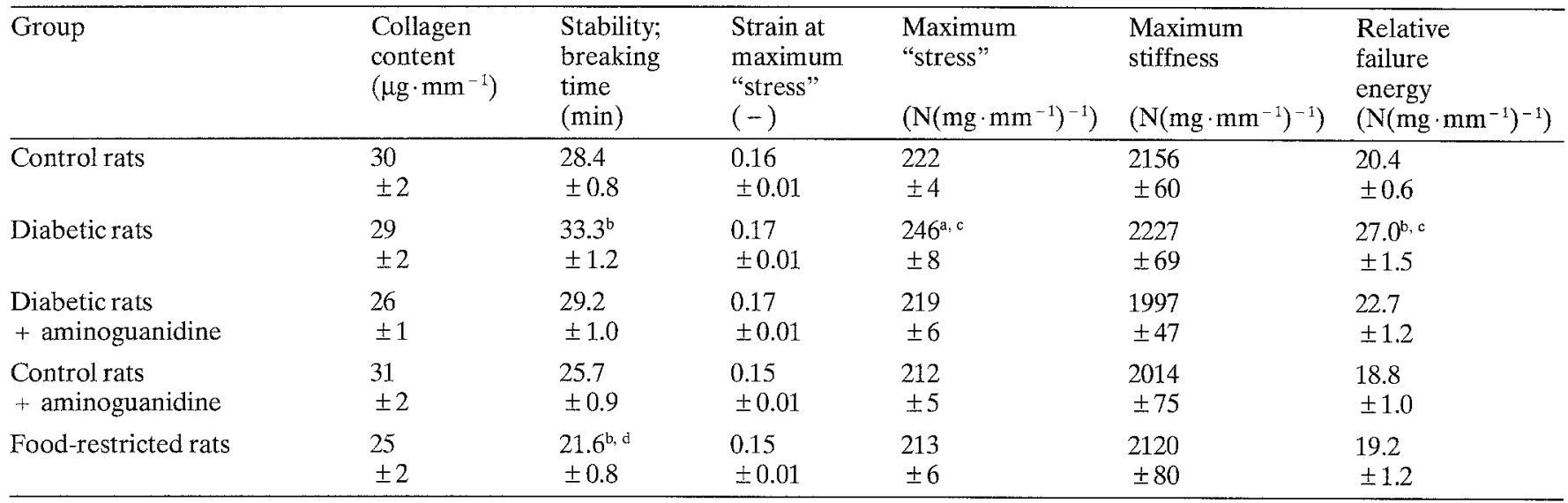

Mean values $\pm \mathrm{SEM} ; \mathrm{N}$, newton; ${ }^{\mathrm{a}} p<0.05$ vs control rats; ${ }^{\mathrm{b}} p<0.01$ vs control rats; ${ }^{\mathrm{c}} p<0.05$ vs diabetic rats + aminoguanidin;

${ }^{\mathrm{d}} p<0.01$ vs diabetic rats 
Table 3. Tritiated borohydride reducible components of tail tendon collagen from diabetic rats treated with aminoguanidine. Tritium activity is normalized to amount of hydroxyproline (hyp)

\begin{tabular}{lllll}
\hline Group & $\begin{array}{l}\text { Hexosyl- } \\
\text { hydroxy- } \\
\text { lysine } \\
\text { (cpm/mg } \\
\text { hyp) }\end{array}$ & $\begin{array}{l}\text { Hexosyl- } \\
\text { lysine } \\
\text { hyp) }\end{array}$ & $\begin{array}{l}\text { Hydroxy- } \\
\text { lysino- } \\
\text { norleucine } \\
\text { (cpm/mg } \\
\text { hyp) }\end{array}$ & $\begin{array}{l}\text { Histidino- } \\
\text { hydroxy- } \\
\text { merodes- } \\
\text { mosine } \\
\text { (cpm/mg } \\
\text { hyp) }\end{array}$ \\
\hline Control rats & 115 & 284 & 455 & 431 \\
& \pm 7 & \pm 13 & \pm 17 & \pm 18 \\
Diabetic rats & $410^{\mathrm{b}}$ & $1006^{\mathrm{b}}$ & $337^{\mathrm{a}}$ & 403 \\
& \pm 35 & \pm 45 & \pm 20 & \pm 9 \\
$\begin{array}{l}\text { Diabetic rats } \\
+ \text { amino- }\end{array}$ & $355^{\mathrm{b}}$ & $867^{\mathrm{b}}$ & $310^{\mathrm{b}}$ & 350 \\
guanidine & \pm 40 & \pm 67 & \pm 20 & \pm 21 \\
Control rats & & & & \\
+ amino- & 124 & 330 & 418 & 413 \\
guanidine & \pm 15 & \pm 67 & \pm 22 & \pm 27 \\
$\begin{array}{l}\text { Food-restricted } \\
\text { rats }\end{array}$ & 112 & 241 & 446 & 382 \\
\hline
\end{tabular}

Mean values $\pm \mathrm{SEM} ;{ }^{\mathrm{a}} p<0.01$ vs control rats; ${ }^{\mathrm{b}} p<0.001$ vs control rats

duced by $7 \%$ of their initial body weight. At killing the weight of diabetic rats treated with aminoguanidine did not differ from that of the non-treated diabetic rats. The weight of control rats treated with aminoguanidine did not differ from that of the control group. Consequently, aminoguanidine treatment did not prevent the weight gain of non-diabetic rats nor did it affect the arrest of weight gain of diabetic rats.

Blood glucose values at killing are given in Table 1 . The diabetic rats had increased blood glucose levels. The aminoguanidine treatment did not affect the blood glucose level in control rats nor did it affect the increased blood glucose level in diabetic rats. No effects of the aminoguanidine treatment were observed on the well-being of the rats.

The weight of the food-restricted rats at killing did not differ from that of the diabetic rats. The food deprivation resulted in a $17 \%$ reduction in the blood glucose level when compared to the control rats.

The hydroxyproline content of the tail tendons is given in Table 2. No differences in the collagen content were found between the groups.

The breaking time of the tail tendons in $7 \mathrm{~mol} / \mathrm{l}$ urea at $40^{\circ} \mathrm{C}$ of diabetic rats was increased compared with that of the control rats (Table 2). The breaking time of tail tendons for aminoguanidine-treated diabetic rats did not differ from that of the control animals, nor did the breaking time of tail tendons from control rats treated with aminoguanidine. No significant difference in breaking time was found between the diabetic groups with and without aminoguanidine treatment $(p<0.07)$. The breaking time of tail tendons from food-restricted rats was reduced compared with that of the control, and compared with that of the diabetic rats.

The biomechanical parameters of the tail tendons are given in Table 2. Values of strain at maximum "stress" and maximum stiffness did not differ between the groups.
The maximum "stress", i.e. tensile strength, and relative failure energy of tail tendons from diabetic rats were increased both when compared with control rats and diabetic rats treated with aminoguanidine.

The borohydride-reduced components of the tail tendon collagen are given in Table 3 and Figure 3. The amounts of hexosyl-hydroxylysine and hexosyl-lysine, representing products of the nonenzymatic glycation, were markedly increased in tail tendons from diabetic rats and diabetic rats treated with aminoguanidine compared with that of the control rats. The amount of the reduced collagen cross-link, HLNL, was decreased in tail tendon collagen from diabetic rats and diabetic rats treated with aminoguanidine. No difference was found in the amount of HHMD. Aminoguanidine treatment of control rats did not affect the amount of hexosyl-hydroxylysine, hexosyllysine or HLNL of tail tendons collagen, indicating that the aminoguanidine treatment did not affect the nonenzymatic glycation or formation of reducible cross-links of rat tail tendon collagen in either control rats or in diabetic rats. No alterations were found in the reducible components of tail tendons collagen from food-restricted rats compared with control rats.

The relative fluorescence of rat tail tendon collagen is shown in Figure 4. The relative fluorescence was markedly increased in tail tendon collagen from diabetic rats both when compared with control rats and diabetic rats treated with aminoguanidine. A significant increase was found in the relative fluorescence of tail tendon collagen of diabetic rats treated with aminoguanidine compared with control rats. No changes in the relative fluorescence were found in tail tendon collagen from control rats treated with aminoguanidine or food-restricted rats compared with the control group. The cyanogen bromide treatment resulted in solubilization of the tail tendon collagen. Only $1-2 \%$ of the total hydroxyproline was found in the pellet after centrifugation, and no differences in the cyanogen bromide solubility were found between the groups.

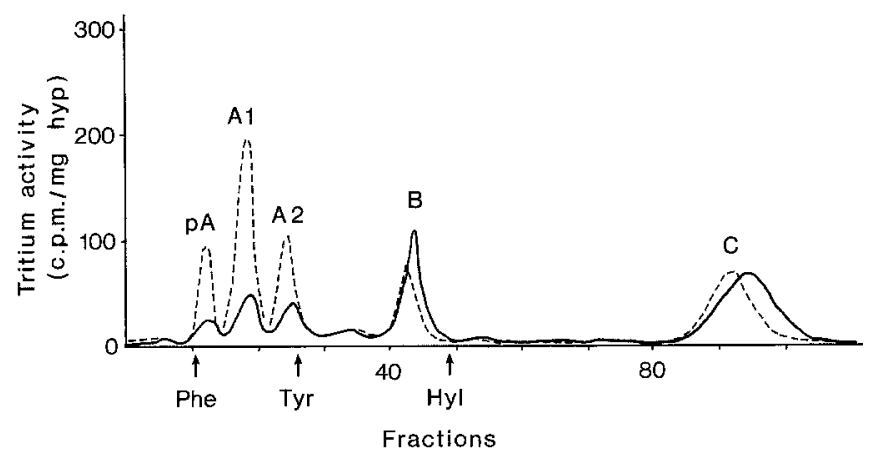

Fig. 3. Tritiated borohydride reducible components of rat tail tendon collagen were analysed by ion-exchange chromatography. pA, hexosyl-hydroxylysine; $\mathrm{A} 1$, hexosyl-lysine; $\mathrm{A} 2$, hexosyl-lysine anhydride are products of the nonenzymatic glycation. $\mathrm{B}$, hydroxylysinonorleucine (HLNL) and C, histidinohydroxymerodesmosine (HHMD) are collagen cross-links. The chromatograms represent control rats (-) and diabetic rats (---). Tritium activity was normalized to amount of hydroxyproline (hyp) 


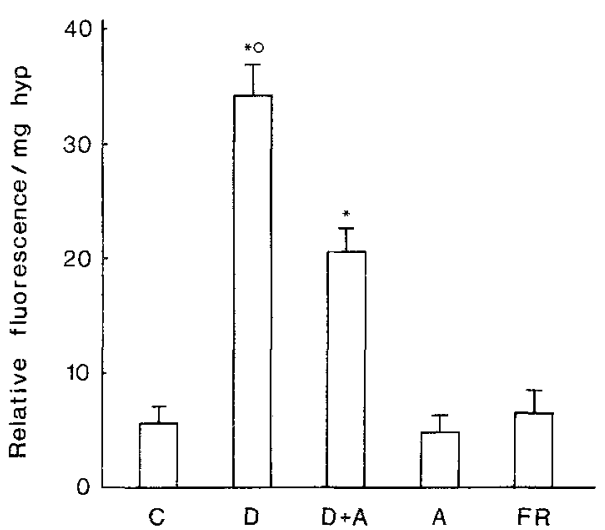

Fig.4. Relative fluorescence of rat tail tendon collagen normalized to amount of hydroxyproline (hyp) in the solution. C, control; D, diabetic; $D+A$, diabetic rats treated with aminoguanidine; $A$, intact rats treated with aminoguanidine and FR, food-restricted rats. $* p<0.001$ against control rats; ${ }^{\circ} p<0.001$ against diabetic rats treated with aminoguanidine

\section{Discussion}

The streptozotocin treatment induced a moderate diabetes with blood glucose concentrations of $16-$ $26 \mathrm{mmol} / \mathrm{l}$ and an arrest of the body weight gain of the rats. The aminoguanidine treatment of diabetic rats did not counteract the increase in blood glucose concentrations, nor did it prevent the arrest in weight gain. The group of non-diabetic rats treated with aminoguanidine had blood glucose concentrations and weight gain just as in the control rats. Therefore, the aminoguanidine treatment itself did not seem to influence these parameters.

The stability and mechanical strength of tail tendons from diabetic rats were increased, which is in agreement with previous studies $[9,10]$. The amount of hexosyllysines (early glycation products) and fluorescent compounds (browning products) expressed in relation to the hydroxyproline content of the tail tendons were markedly increased. The increased stability and mechanical strength might be caused by the increased nonenzymatic glycation and subsequent formation of cross-links derived from the glucosyl-lysines, i.e. browning products, some of which are fluorescent. This view is supported by studies on the stability of collagen from rats with experimental diabetes [24-26] and by studies of in vitro incubation of rat tail tendons with glucose $[5-8,24,27]$.

Diabetic rats treated with daily injections of aminoguanidine showed no increase in stability and mechanical strength of their tail tendons when compared with the control rats. The nonenzymatic glycation of the collagen was still markedly increased, while the amount of fluorescent compounds in the collagen was reduced. Therefore, aminoguanidine treatment of diabetic rats reduces the formation of fluorescent compounds and prevents the alterations in the biophysical properties of collagen. These findings are in agreement with those of Brownlee et al. [12]. They showed that aminoguanidine treatment $\left(25 \mathrm{mg} \cdot \mathrm{kg}^{-1} \cdot \mathrm{day}^{-1}\right)$ of diabetic rats for 4 months prevented the diabetes-induced formation of fluorescent advanced glycation end-products cross-linking the arterial wall proteins.
Likewise, aminoguanidine has been shown to prevent the accumulation of fluorescent compounds in rat skin collagen [28] and collagen from renal basement membranes [29]. Diabetic mice treated with an amino acid consisting of a guanidino group on a carbon skeleton, also expected to block reactive carbonyle groups resulted in less cross-linked collagen from renal basement membranes [30]. The nonenzymatic glycation of matrix components produced by renal mesangial cells in culture incubated with glycolaldehyde or glucose-6-phosphate was prevented by aminoguanidine [31]. This is in contrast to the present in vivo study, in which aminoguanidine treatment of diabetic rats did not prevent the nonenzymatic glycation of collagen, but still reduced the formation of fluorescent compounds and thereby the cross-linking of proteins. Consequently, formation of browning products (advanced glycation end-products) cannot be monitored by measurement of the early nonenzymatic glycation products (aldimine and Amadori rearrangement products). This emphasizes the importance of elaborating a specific method for determination of glucose-derived cross-linking products in tissue samples.

Collagens are relatively long-lived proteins which are located extracellularly and are therefore exposed to elevated concentrations of glucose. It has been shown that collagen from diabetic patients has decreased solubility when treated with acid and pepsin [32, 33]. Kohn [34] showed that insoluble collagen from patients with diabetes released fewer peptides when treated with cyanogen bromide, confirming the increased cross-linking of collagen in diabetic subjects. Increased glycation of collagen has been described [35-37] and accumulation of fluorescent compounds $[37,38]$ and it has been proposed that these products of the nonenzymatic glycation form stabile irreversible cross-links between the collagen molecules, resulting in biomechanically rigid structures $[1,11,37]$.

The therapeutic use of aminoguanidine as a treatment for diabetic patients is under investigation $[39,40]$. In any case, aminoguanidine seems to be a useful drug in the further study of a possible relation between increased nonenzymatic glycation, cross-linking of proteins and development of chronic complications.

The reducible collagen cross-link, HLNL, which is found in rat tail tendon collagen, was present at lower levels in diabetic rats and this decrease was not influenced by the aminoguanidine treatment. HLNL stems mainly from newly deposited collagen and this decrease therefore could be explained by a decreased collagen deposition in diabetic rats or by a decrease in the lysyl oxidase activity. It has been shown in vitro that the activity of this enzyme is decreased when the glucose concentration is increased [41]. The reducible cross-link, HLNL, may be coupled to a histidine residue in a neighbouring molecule resulting in a mature stabile cross-link, HHLNL [42]. Theoretically, the reduced amount of HLNL, therefore, might be caused by an increased formation of HHLNL. At present we do not know what causes this reduction in the amount of HLNL in diabetic rats, but it seems likely that it is caused by a reduced synthesis of collagen $[43,44]$. No differences were found in the mature collagen cross-link HHMD. 
The food-restricted group was included in the experiment because experimental diabetes is known to arrest the weight gain of rats or even induce a weight loss. Therefore, we included a control group which was food restricted so as to achieve the same weight as the diabetic group. Only one parameter of tail tendons from the foodrestricted group differed from those of the control group. Consequently, the increased stability, strength, nonenzymatic glycation and fluorescence could not be explained by a reduced weight gain of the rats.

The stability and mechanical strength of tail tendon collagen from rats with moderate experimental diabetes were increased accompanied by a marked increase in the nonenzymatic glycation and increased content of fluorescent compounds of the collagen. Aminoguanidine treatment seems to inhibit the formation of fluorescent compounds derived from the nonenzymatic glycation products and prevent the increase in stability and mechanical strength which are observed in collagen from diabetic rats. These findings indicate that the biophysical alterations of collagen induced by experimental diabetes are caused by cross-links derived from the nonenzymatic glycation. Furthermore, we find that aminoguanidine is a useful drug for future studies of a possible relation between nonenzymatic glycation, cross-linking of proteins and development of chronic diabetic complications.

Acknowledgements. This investigation was supported by the Danish Diabetes Association, Kong Christian Den Tiendes Fond and the NOVO Foundation. Aminoguanidine was kindly provided by Prof. A. Cerami, Laboratory of Medical Biochemistry, The Rockefeller University, New York, USA. The authors wish to thank Mr. N. Kappel, Ms. L.P.Kristensen and Ms. C. Knæhus for skilled technical assistance, and Ms. Aa. Young for linguistic revision.

\section{References}

1. Brownlee M, Cerami A, Vlassara H (1988) Advanced glycosylation end products in tissue and the biochemical basis of diabetic complications. N Engl J Med 318: 1315-1321

2. Monnier VM, Vishwanath V, Frank KE, Elmets CA, Dauchot P, Kohn RR (1986) Relation between complications of type I diabetes mellitus and collagen-linked fluorescence. $\mathrm{N}$ Engl J Med 314:403-408

3. Monnier VM (1990) Nonenzymatic glycosylation, the Maillard reaction and the aging process. J Gerontol 45: B105-B 111

4. Reiser KM (1991) Nonenzymatic glycation of collagen in aging and diabetes. Proc Soc Exp Med 196: 17-29

5. Andreassen TT, Oxlund H (1985) Thermal stability of collagen in relation to non-enzymatic glycosylation and browning in vitro. Diabetologia 28: 687-691

6: Kent MJC, Light ND, Bailey AJ (1985) Evidence for glucosemediated covalent cross-linking of collagen after glycosylation in vitro. Biochem J 225: 745-752

7. Andreassen TT, Oxlund H, Danielsen CC (1988) The influence of non-enzymatic glycosylation and formation of fluorescent reaction products on the mechanical properties of rat tail tendons. Conn Tissue Res 17: 1-9

8. Menzel EJ, Reihsner R (1991) Alterations of biochemical and biomechanical properties of rat tail tendon caused by non-enzymatic glycation and their inhibition by dibasic amino acids arginine and lysine. Diabetologia 34: 12-16
9. Galeski A, Kastelic J, Baer E, Kohn RR (1977) Mechanical and structural changes in rat tail tendon induced by alloxan diabetes and aging. J Biomech 10: 775-782

10. Andreassen TT, Seyer-Hansen K, Bailey AJ (1981) Thermal stability, mechanical properties and reducible cross-links of rat tail tendon in experimental diabetes. Biochim Biophys Acta 677: 313-317

11. Oxlund H, Rasmussen LM, Andreassen TT, Heickendorff L (1989) Increased aortic stiffness in patients with Type 1 (insulindependent) diabetes mellitus. Diabetologia 32: 748-752

12. Brownlee M, Vlassara H, Kooney A, Ulrich P, Cerami A (1986) Aminoguanidine prevents diabetes-induced arterial wall protein cross-linking. Science 232: 1629-1632

13. Khatami M, Suldan Z, David I, Li W, Rockey JH (1988) Inhibitory effects of pyridoxal phosphate, ascorbate and aminoguanidine on nonenzymatic glycosylation. Life Sci 43: 1725-1731

14. Andreassen TT, Oxlund H (1987) Changes in collagen and elastin of the rat aorta induced by experimental diabetes and food restriction. Acta Endocrinol 115:338-344

15. Boros-Farkas M, Everitt AV (1967) Comparative studies of age tests on collagen fibres. Gerontologia 13: 37-49

16. Oxlund H, Andreassen TT (1980) The roles of hyaluronic acid, collagen and elastin in the mechanical properties of connective tissues. J Anat 131: 611-620

17. Stegman H, Stalder K-H (1967) Determination of hydroxyproline. Clin Chim Acta 18: 267-273

18. Bailey AJ, Peach CM, Fowler LJ (1970) Chemistry of the collagen cross-links. Biochem J 117:819-831

19. Robins SP, Shimokomaki M, Bailey AJ (1973) The chemistry of the collagen cross-links. Age-related changes in the reducible components of intact bovine collagen fibres. Biochem $\mathbf{J} 131$ : $771-780$

20. Oxlund H, Sims T, Light ND (1982) Changes in mechanical properties, thermal stability, reducible cross-links and glycosyllysines in rat skin induced by corticosteroid treatment. Acta Endocrinol 101: 312-320

21. Robins SP (1976) The separation of cross-linking components from collagen. In: Hall DA (ed) The methodology of connective tissue research. Joynson-Bruvvers, Oxford, pp 37-52

22. Oxlund H, Holmberg Jørgensen P, Ørtoft G, Andreassen TT (1991) Alternations in the cross-links of skin collagen of rats treated with biosynthetic growth hormone. Conn Tis Res 26: $65-75$

23. Sokal RR, Rohlf FJ (1981) Biometry. Freeman, San Francisco

24. Yue DK, McLennan S, Delbridge L, Handelsman DJ, Reeve T, Turtle JR (1983) The thermal stability of collagen in diabetic rats: correlation with severity of diabetes and non-enzymatic glycosylation. Diabetologia 24: 282-285

25. Yue DK, McLennan S, Handelsman DJ, Delbridge L, Reeve T, Turtle JR (1984) The effect of salicylates on nonenzymatic glycosylation and thermal stability of collagen in diabetic rats. Diabetes 33: 745-751

26. Yosha SF, Elden HR, Rabinovitch A, Mintz DH, Boucek RJ (1983) Experimental diabetes mellitus and age-stimulated changes in intact rat dermal collagen. Diabetes 32: 739-742

27. Kohn RR, Cerami A, Monnier VM (1984) Collagen aging in vitro by nonenzymatic glycosylation and browning. Diabetes 33: $57-59$

28. Odetti PR, Borgoglio A, De Pascale A, Rolandi R, Adezati L (1990) Prevention of diabetes-increased aging effect on rat collagen-linked fluorescence by aminoguanidine and rutin. Diabetes 39: 796-801

29. Nicholls K, Mandel TE (1989) Advanced glycosylation end-products in experimental murine diabetic nephropathy: effect of islet isografting and of aminoguanidine. Lab Invest 60: 486-491

30. Lubec G, Bartosch B, Mallinger R et al. (1990) The effect of substance $L$ on glucose-mediated cross-links of collagen in the diabetic $\mathrm{db} / \mathrm{db}$ mouse. Nephron 56: 281-284

31. Crowley ST, Brownlee M, Edelstein D et al. (1991) Effects of nonenzymatic glycosylation of mesangial matrix on proliferation of mesangial cells. Diabetes 40: 540-547 
32. Schnider SL, Kohn RR (1981) Effects of age and diabetes mellitus on the solubility and nonenzymatic glucosylation of human skin collagen. J Clin Invest 67: 1630-1635

33. Salmela PI, Oikarinen A, Pirttiaho H, Knip M, Niemi M, Ryhänen L (1989) Increased non-enzymatic glycosylation and reduced solubility of skin collagen in insulin-dependent diabetic patients. Diab Res 11: 115--120

34. Kohn RR (1983) Effects of age and diabetes mellitus on cyanogen bromide digestion of human dura mater collagen. Conn Tissue Res 11: 169-173

35. Vogt BW, Schleicher ED, Wieland OH (1982) $\varepsilon$-amino-lysinebound glucose in human tissues obtained at autopsy. Increase in diabetes mellitus. Diabetes 31: 1123-1127

36. Monnier VM, Cerami A (1982) Nonenzymatic glycosylation and browning in diabetes and aging. Diabetes 31:57-63

37. Monnier VM, Kohn RR, Cerami A (1984) Accelerated age-related browning of human collagen in diabetes mellitus. Proc Natl Acad Sci 81: 583--587

38. Sell DR, Monnier VM (1989) Isolation, purification and partial characterization of novel fluorophores from aging human insoluble collagen-rich tissue. Conn Tissue Res 19:77-92

39. Makita Z, Radoff S, Rayfield E (1990) Radioreceptor assay (PRA) for human serum and arterial tissue advanced glycosylation endproducts (AGE), Diabetes 39:29A
40. Giardino I, Brownlee M (1991) Glycosylation inhibition. In: Mogensen CE, Standl E (eds) Pharmacology of diabetes. Present practice and future perspectives. de Gruyter, Berlin, pp 211-220

41. Lien Y-H, Stern R, Fu JCC, Siegel R (1984) Inhibition of collagen fibril formation in vitro and subsequent cross-linking by glucose. Science 225: 1489-1491

42. Yamauchi M, Woodley DT, Mechanic GL (1988) Aging and cross-linking of skin collagen. Biochem Biophys Res Commun 152: $898-903$

43. Bowersox JC (1986) In vivo collagen metabolism in spontaneously diabetic (db/db) mice. Exp Mol Pathol 45:221-226

44. Spanheimer RG, Umpierrez GE, Stumpf V (1988) Decreased collagen production in diabetic rats. Diabetes $37: 371-376$

Received: 8 July 1991

and in revised form: 16 September 1991

Dr. H. Oxlund

Department of Connective Tissue Biology

Institute of Anatomy

University of Aarhus

DK-8000 Aarhus C

Denmark 